catecholamines

lipids

newborns norepinephrine

oxygen

consumption

\title{
Catecholamine-induced Lipolysis and Its Relation to Oxygen Consumption in the Newborn Piglet
}

\author{
Bengt Persson ${ }^{[38]}$, Johan C. H. Gentz, Jussi Hakkarainen, and Michael Kellum \\ Department of Pediatrics, Karolinska Institutet; S:t Göran's Children's Hospital; and the Department of Animal Nutrition, \\ Hygiene, and Genetics, Royal Veterinary College, Stockholm, Sweden
}

\section{Extract}

The relation between changes in oxygen consumption $\left(\mathrm{VO}_{2}\right)$ (in milliliters per kilogram and minute) and changes in levels of free fatty acids (FFA) and glycerol in plasma, lactate, pyruvate, and glucose levels in blood, and skin and rectal temperatures following norepinephrine or epinephrine infusions has been studied in neonatal piglets who lack brown fat and rapidly increase their body fat content after birth. Fourteen animals, age $17 \mathrm{hr}-13$ days (Table $\mathrm{I} A$ ), each received two 25-min infusions of 2.0 $\mu \mathrm{g} / \mathrm{kg} \cdot \mathrm{min}$ of norepinephrine (see Fig. 3); nicotinic acid (50 mg/kg) was administered prior to the second infusion. Five animals, age $5 \mathrm{hr}-11$ days (Table $\mathrm{I} B$ ), each received two infusions of $0.2-4.0 \mu \mathrm{g} / \mathrm{kg} \cdot \mathrm{min}$ of epinephrine (Fig. 5).

The elevated levels of glucose in blood, and FFA and glycerol concentrations in plasma observed following norepinephrine infusions correlated with postnatal age and body weight, suggesting that the magnitude of the norepinephrine-induced lipid mobilization was dependent upon body fat content. There was no definite tendency for $\mathrm{VO}_{2}$ responses to norepinephrine to increase with increasing postnatal age (Table I $A$ ). The increases in glycerol levels (Fig. 2) and FFA (Fig. 1) concentrations occurring after norepinephrine stimulation were suppressible by nicotinic acid.

The increases in $\mathrm{VO}_{2}$ occurring after norepinephrine infusion (Table $\mathrm{I} A$ ) were small (mean of 0.85 and $0.57 \mathrm{ml} / \mathrm{kg} \cdot$ min during infusion prior to and following nicotinic acid administration, respectively) and variable and did not appear to be accentuated by previous starvation for $48 \mathrm{hr}$; they were related neither to elevations of any of the biochemical variables monitored nor to the small increases in skin and rectal temperatures observed. The changes in $\mathrm{VO}_{2}$ after epinephrine infusions (Table $\mathrm{I} B$ ) were quantitatively similar to those recorded during norepinephrine infusions and were not correlated to changes in concentrations of glucose, plasma FFA or glycerol (Fig. 5).

\section{Speculation}

The findings in the piglet, of small increases in $\mathrm{VO}_{2}$ after norepinephrine infusion and the lack of a significant lowering of $\mathrm{VO}_{2}$ response when norepinephrine challenge was preceded by nicotinic acid administration, contrast with those observed in adults of other species studied and preliminary results found in older piglets. It is therefore suggested that the newborn piglet has a relative inability to increase oxidation of norepinephrine-mobilized FFA and that this may improve with increasing postnatal age. 


\section{Introduction}

The calorigenic effect of norepinephrine in the neonatal period has received increasing attention since the recognition of an association between sympathetic amines and the thermogenic response of the newborn. In certain species, such as the rabbit and guinea pig, the major portion of either cold-induced or norepinephrine-induced calorigenesis can be attributed to the effects of norepinephrine on brown adipose tissue $[7,27]$. In older individuals of other species, however, it has been proposed that at least a portion of this response to norepinephrine can be attributed to oxidative utilization of free fatty acids mobilized from white adipose tissue $[10,15,28]$.

In the newborn human infant, cold exposure results in an increased excretion of catecholamines [23, 24], and norepinephrine infusion to infants studied in the thermoneutral zone effects an increase in oxygen consumption and body temperature $[16,24]$. The relative importance of possible mechanisms involved in calorigenesis in the newborn human, however, remains to be defined. Furthermore, since the newborn human is born with both white and brown adipose tissue, the differentiation of their relative roles in this response to catecholamines is indecd difficult.

Newborn piglets lack brown fat at birth [8] and rapidly increase their body stores of fat, and therefore presumably white adipose tissuc, after birth [17]. Thus, they are an excellent experimental animal in which to study the relations among body fat content, postnatal age, and catecholamine-induced lipolysis and calorigenesis. Nicotinic acid was used in some of the expcriments to clarify these relations further. This drug is known to inhibit norepinephrine-induced lipolysis [4]. In addition, a comparison has becn made between epinephrine- and norepinephrine-induced calorigenesis.

\section{Materials and Methods}

A total of 19 piglets, $5 \mathrm{hr}-13$ days of age, from 5 Swedish Landrace sows were studied. Their deliveries and gestational periods were normal. With the exception of two animals who were starved for $48 \mathrm{hr}$, all were allowed to suckle at will until 3-4 $\mathrm{hr}$ prior to the investigation. They were then removed from the sow and kept in temperature-controlled individual pens [1]. The weights of all piglets when studied were, except for the two starved animals, within the normal range of values for Swedish Landrace piglets of comparable ages at our department.

\section{Determination of Oxygen Consumption and Temperature}

Oxygen consumption rate was measured under carefully controlled environmental conditions in a closed circuit apparatus where $\dot{\mathrm{VO}}_{2}$ was registered as the volume change after absorption of carbon dioxide [13]. The decrease in volume was continuously compensated for by fecding oxygen into the system via a "float" mechanism sensitive to volume changes within the system. The $\mathrm{VO}_{2}$ was determined by measuring the time needed to empty the float; this ranged from approximately 1 to $5 \mathrm{~min}$, depending upon the size of the animals and the preset emptying volume (usually $45-65 \mathrm{ml}$ ). The mean value (time per volume) from at least five emptyings of the float was calculated and transformed into $\mathrm{VO}_{2}$. All volumes were expressed at standard temperature and pressure (STPD). For a piglet in steady state, the variation in $\dot{\mathrm{VO}}_{2}$ (in milliliters per kilogram and minute) measured over a 5 -min period was $\pm 1.0 \%$. Temperature gradients in the empty chamber were small (maximum of $0.4^{\circ}$ ), and, during operation, temperature variations at different sites were not measurable. The relative humidity was kept constant during each observation; it varied between experiments from 25 to $35 \%$.

Temperatures were measurcd by thermocouples and continuously recorded on a strip chart recorder [29]. They included rectal temperature (probe inserted at least $5 \mathrm{~cm}$ ), skin temperature (measured $2 \mathrm{~cm}$ below the umbilicus in the midline), and wet and dry temperatures of the air entering the chamber. The environmental temperature reported is that of the dry bulb.

Most animals remained calm and relatively immobile in the experimental chamber; however, some demonstrated periods of excessive motor activity both spontaneously and after catecholamine infusions. These periods were characterized by intermittent short bursts of jerky straining movements. Care was taken to exclude, as far as possible, these periods from the results.

\section{Chemical Methods}

Free fatty acid and glyccrol levels in plasma, and glucose concentrations in blood were determined according to previously described methods [1]. Levels of lactate and pyruvate were determined by a modified enzymatic method [25]. $\beta$-Hydroxybutyrate was determined by an enzymatic micromethod [20]. Methodological errors for FFA, glycerol, glucose, lactate, pyruvate, and $\beta$-hydroxybutyrate were below $5 \%$.

\section{Procedure}

Before the animals were placed in the experimental chamber, they were weighed and ticd in supine position on a Perspex tray, a catheter was inserted into each internal jugular vein under local anaesthesia, lidocaine, $0.5 \%$ [30], and thermocouples were sccured in place. Thev 
were studied at an environmental temperature within their thermoneutral zone [11]. After a satisfactory interval within the chamber to effect steady-state conditions (30-35 $\mathrm{min}$ ), continuous monitoring of oxygen consumption and temperatures was begun, and initial blood samples were drawn. All intravenous infusions were given at a rate of $6 \mathrm{ml} / \mathrm{hr}$ with a continuous infusion apparatus [31]. Sodium chloride solution $(0.15 \mathrm{M})$ was administered before and after catecholamine infusions.

\section{Blood Collection}

Blood samples (1.2-1.5 ml/sample) were drawn from the jugular catheter not used for infusions. No heparin was administered. Blood was transferred in to heparinized tubes, and aliquots were immediately deproteinized; portions were also taken for hematocrit determinations. The remaining blood was kept at $+4^{\circ}$ until centrifugation. Plasma was then stored at $-20^{\circ}$ for subscquent analyses of FFA, glycerol, and $\beta$-hydroxybutyrate.

\section{Experimental Protocols}

Fourtcen piglets (Table $\mathrm{I} A$ ) received $2.0 \mu \mathrm{g} / \mathrm{kg} \cdot \min$ of norepinephrine [32] intravenously (dose in units of base) during two 25-min infusion periods with a 60 -min interval intervening. A total of $50 \mathrm{mg} / \mathrm{kg}$ of nicotinic acid [33] was administered intravenously in five divided bolus doses at 30,20,10,5, and 2 min preceding the second norepinephrine infusion (Fig. 3).
Five piglets (Table $I B$ ) received infusions of epinephrine [34]. The protocol (Fig. 5) was similar in time sequence to that of the previous 14 animals, but no nicotinic acid was given.

\section{Results}

\section{Norepinephrine Infusions}

The data for birth weight, age and weight at test, and skin and rectal and environmental temperatures for the 14 animals given $2.0 \mu \mathrm{g} / \mathrm{kg} \cdot \mathrm{min}$ norepinephrine before and after nicotinic acid administration are given in Table I $A$.

The individual data for $\dot{\mathrm{VO}}_{2}$ (Table $\mathrm{I} A$ ) and biochemical variables (Tables II $A$ and II $B$ ) are presented for the following four experimental periods: control (BASAL), first norepinephrine infusion (NE I), nicotinic acid administration (NIAC), and the norepinephrine infusion following nicotinic acid administration (NE II). The values for $\mathrm{VO}_{2}$ given in Table $\mathrm{I} A$ represent the means of the individual calculations for any particular period. This method of expressing $\mathrm{V}_{2}$ was chosen because there were no consistent temporal patterns of changes in $\dot{\mathrm{VO}}_{2}$ for the animals during stimulation periods allowing meaningful comparisons of "peak" $\mathrm{VO}_{2}$. The values given for the biochemical variables in the BASAL and NIAG periods in Tables II $A$ and II $B$ represent the means of the last two determinations in each period (individual

Table IA. Oxygen consumption of piglets under various experimental conditions

\begin{tabular}{|c|c|c|c|c|c|c|c|c|c|c|}
\hline \multirow{2}{*}{\multicolumn{5}{|c|}{ Animal data }} & \multicolumn{6}{|c|}{ Experimental periods ${ }^{1}$} \\
\hline & & & & & \multicolumn{3}{|c|}{ BASAL } & NE I & \multirow{2}{*}{$\frac{\mathrm{NIAC}}{\mathrm{VO}_{2} \mathrm{z}}$} & \multirow[t]{2}{*}{ NE II } \\
\hline Pig no. & $\begin{array}{c}\text { Birth } \\
\text { wt, } \mathrm{kg}\end{array}$ & $\begin{array}{l}\text { Weight at } \\
\text { test, } \mathrm{kg}\end{array}$ & $\begin{array}{c}\text { Age at } \\
\text { test, days }\end{array}$ & $T_{E^{2}}$ & $\mathrm{~T}_{\mathrm{R}^{2}}$ & $\mathrm{~T}_{\mathrm{s}^{2}}$ & $\mathrm{CO}_{2}{ }^{3}$ & & & \\
\hline 1 & 1.40 & 1.40 & $17 / 24$ & 34.5 & 38.0 & 38.0 & 6.9 & 7.3 & 7.0 & 6.9 \\
\hline 2 & 1.60 & 1.68 & 1654 & 34.0 & 39.8 & 39.8 & 13.6 & 14.8 & 13.7 & 14.0 \\
\hline 3 & 1.51 & 1.72 & $21 / 2$ & 32.8 & 40.0 & 40.0 & 14.5 & 16.7 & 14.5 & 15.6 \\
\hline 4 & 1.22 & 1.83 & $41 / 2$ & 31.9 & 39.8 & 39.4 & 16.2 & 16.4 & 16.3 & 16.9 \\
\hline 5 & 1.48 & 1.92 & 5 & 29.5 & 39.1 & & 16.4 & 16.7 & 15.3 & 15.4 \\
\hline 6 & 1.26 & 2.14 & 5 & 27.1 & 39.0 & 39.0 & 18.4 & 18.0 & 17.5 & 19.3 \\
\hline 7 & 2.00 & 2.10 & 5 & 27.7 & 37.3 & 37.4 & 10.9 & 10.8 & 9.9 & 10.2 \\
\hline 8 & 1.03 & 1.90 & 6 & 26.7 & & & 20.2 & 20.6 & 20.7 & 20.3 \\
\hline 9 & 2.00 & 2.31 & 7 & 27.3 & & 37.8 & 10.7 & 11.8 & 10.8 & 11.8 \\
\hline 10 & 1.79 & 2.55 & 8 & 27.3 & 39.2 & 38.3 & 15.2 & 16.3 & 14.5 & 17.4 \\
\hline 11 & 1.38 & 3.54 & 8 & 25.0 & 39.7 & 38.9 & 17.9 & 19.4 & 19.5 & 18.2 \\
\hline 12 & 0.82 & 1.77 & 10 & 28.5 & & & & & & \\
\hline 13 & 1.24 & 3.44 & 10 & 25.5 & 40.0 & 39.0 & 18.5 & 19.9 & 17.9 & 17.9 \\
\hline 14 & 1.13 & 3.15 & 13 & 26.5 & 39.5 & 39.4 & 14.9 & 16.7 & 15.2 & 16.3 \\
\hline
\end{tabular}

1 See experimental protocols in Methods for definition of dosages and periods.

${ }^{2}$ Environmental, rectal, and skin temperatures in degrees centigrade; $T_{E}, T_{R}$, and $T_{S}$, respectively, during the BASAL (control) period.

${ }^{3}$ Oxygen consumption is expressed as $\mathrm{VO}_{2}$ in $\mathrm{ml} / \mathrm{kg} \cdot \mathrm{min}$ STPD. 
Table IB. Oxygen consumption data for piglets given infusions of epinephrine

\begin{tabular}{|c|c|c|c|c|c|c|c|c|c|c|c|}
\hline & & & & & \multicolumn{7}{|c|}{ Experimental periods ${ }^{2}$} \\
\hline \multicolumn{5}{|c|}{ Animal data } & \multicolumn{3}{|c|}{ BASAL I } & \multirow[t]{2}{*}{ E I } & \multirow{2}{*}{$\frac{\text { BASAL II }}{\dot{\mathrm{VO}}_{2}}$} & \multirow[t]{2}{*}{ E II } & \multirow{2}{*}{$\begin{array}{c}\text { Dose, } \\
\mu \mathrm{g} / \mathrm{kg} \cdot \min \end{array}$} \\
\hline Pig no. & $\begin{array}{c}\text { Birth } \\
\text { wt, } \mathrm{kg}\end{array}$ & $\begin{array}{c}\text { Weight at } \\
\text { test, } \mathrm{kg}\end{array}$ & $\begin{array}{c}\text { Age at } \\
\text { test, days }\end{array}$ & $\mathbf{T}_{\mathbf{E}}$ & $\mathrm{T}_{\mathrm{R}}$ & $T_{B}$ & $\dot{\mathrm{v}}_{2}$ & & & & \\
\hline 15 & 1.25 & 1.25 & $5 / 24$ & 34.5 & 38.6 & 38.5 & 7.7 & 8.7 & 8.8 & 8.1 & $2.0 / 4.0$ \\
\hline 16 & 1.72 & 2.98 & 8 & 27.2 & 38.8 & 39.1 & 14.0 & 15.2 & 14.0 & 15.2 & $0.2 / 1.0$ \\
\hline 17 & 1.68 & 3.03 & 8 & 26.8 & 39.7 & 39.6 & 16.1 & 16.5 & 15.8 & 16.4 & $0.4 / 0.4$ \\
\hline 18 & - & 1.98 & 8 & 27.5 & 39.7 & 39.3 & 18.1 & 20.7 & 19.0 & 19.3 & $2.0 / 2.0$ \\
\hline 19 & 1.51 & 3.51 & 11 & 25.6 & 38.6 & 37.9 & 13.7 & 13.7 & 14.3 & 14.2 & $0.8 / 0.8$ \\
\hline
\end{tabular}

${ }^{1}$ See text for definition of periods. Descriptive data and $\dot{\mathrm{VO}}_{2}$ expressed as in Table IA. Control periods, BASAL I and BASAL II, precede the respective epinephrine infusion periods $E$ I and E II.

2 Epinephrine doses administered in E I and E II.

Table IIA. Biochemical data

\begin{tabular}{|c|c|c|c|c|c|c|c|c|c|c|c|c|c|c|c|c|}
\hline \multicolumn{17}{|c|}{ Experimental periods ${ }^{1}$} \\
\hline \multirow[b]{2}{*}{$\begin{array}{l}\text { Pig } \\
\text { no. }\end{array}$} & \multicolumn{4}{|c|}{ BASAL } & \multicolumn{4}{|c|}{$\mathrm{NEI}$} & \multicolumn{4}{|c|}{ NIAC } & \multicolumn{4}{|c|}{ NE II } \\
\hline & $\begin{array}{c}\mathrm{FFA}^{2} \\
\mathrm{mmol}\end{array}$ & $\begin{array}{l}\text { Gly² } \\
\text { /liter }\end{array}$ & $\begin{array}{c}\mathrm{Glu}^{2}{ }^{2} \\
\mathrm{mg} / 100 \\
\mathrm{ml}\end{array}$ & $\underset{\%}{\mathrm{Htc},}$ & $\begin{array}{l}\text { FFA } \\
\text { mmo }\end{array}$ & $\begin{array}{r}\text { Gly } \\
\text { s/liter }\end{array}$ & $\underset{\substack{\mathrm{Gg} / 100 \\
\mathrm{ml}}}{\mathrm{Glu}}$ & $\underset{\%}{\mathrm{Htc},}$ & $\begin{array}{l}\text { FFA } \\
\text { mmol }\end{array}$ & $\begin{array}{l}\text { Gly } \\
\text { s/liter }\end{array}$ & $\underset{\substack{\mathrm{mg} / 100}}{\mathrm{Glu}}$ & $\underset{\%}{\text { Ittc, }}$ & $\begin{array}{l}\text { FFA } \\
\text { mmol }\end{array}$ & $\begin{array}{l}\text { Gly } \\
\text { s/liter }\end{array}$ & $\underset{\substack{\mathrm{mg} / 100 \\
\mathrm{ml}}}{\mathrm{Glu}}$ & $\underset{\%}{\text { Htc, }}$ \\
\hline 1 & 0.14 & 0.042 & 37 & 35 & 0.17 & 0.063 & 56 & 37 & 0.14 & 0.023 & 51 & 34 & 0.12 & 0.025 & 74 & 35 \\
\hline 2 & 0.26 & 0.101 & 68 & 31 & 0.39 & 0.174 & 100 & 31 & 0.09 & 0.041 & 72 & 27 & 0.11 & 0.047 & 87 & 30 \\
\hline 3 & 0.18 & 0.046 & 67 & 23 & 0.33 & 0.063 & 83 & 25 & 0.14 & 0.012 & 76 & 19 & 0.14 & 0.035 & 108 & 21 \\
\hline 4 & 0.34 & 0.078 & 74 & 19 & 0.70 & 0.222 & 127 & 22 & 0.16 & 0.083 & 94 & 19 & 0.25 & 0.115 & 90 & 19 \\
\hline 5 & 0.29 & 0.121 & 74 & 27 & 0.52 & 0.250 & 133 & 29 & 0.19 & 0.081 & 95 & 22 & 0.42 & 0.222 & 143 & 26 \\
\hline 6 & 0.33 & & 83 & 31 & 1.16 & & 112 & 32 & 0.15 & & 71 & 29 & 0.60 & & 244 & 29 \\
\hline 7 & 0.17 & 0.031 & 82 & 21 & 0.78 & 0.088 & 139 & 23 & 0.11 & 0.035 & 150 & 19 & 0.23 & 0.042 & 205 & 21 \\
\hline 8 & 0.33 & & 84 & 27 & 1.21 & & 133 & 27 & 0.18 & & 95 & 26 & 0.73 & & 148 & 26 \\
\hline 9 & 0.15 & 0.021 & 83 & 33 & 1.06 & 0.131 & 146 & 36 & 0.16 & 0.020 & 133 & 32 & 0.22 & 0.042 & 192 & 35 \\
\hline 10 & 0.27 & 0.078 & 68 & 31 & 0.72 & 0.215 & 127 & 32 & 0.19 & 0.047 & 77 & 29 & 0.20 & 0.002 & 119 & 30 \\
\hline 11 & 0.34 & & & 37 & 1.40 & & & 38 & 0.28 & & & 36 & 0.43 & & & 37 \\
\hline 12 & 0.27 & & 106 & 33 & 0.88 & & 188 & 32 & 0.18 & & 137 & 30 & 0.31 & & 182 & 31 \\
\hline 13 & 0.30 & 0.123 & 107 & 17 & 1.37 & 0.274 & 217 & 17 & 0.22 & 0.094 & 142 & 15 & 0.44 & 0.137 & 206 & 15 \\
\hline 14 & 0.34 & 0.126 & 96 & 14 & 1.22 & 0.332 & 180 & 14 & 0.14 & 0.081 & 99 & 13 & 0.25 & 0.120 & 159 & 13 \\
\hline
\end{tabular}

See text for definition of periods and abbreviations

FF A : free fatty acids; Gly: glycerol; Glu: glucose.

Table IIB. Biochemical data

\begin{tabular}{|c|c|c|c|c|c|c|c|c|c|c|c|c|}
\hline \multirow{4}{*}{ Pig no. } & \multicolumn{9}{|c|}{ Experimental periods ${ }^{1}$} & & & \\
\hline & \multicolumn{3}{|c|}{ BASAL } & \multicolumn{3}{|c|}{ NE I } & \multicolumn{3}{|c|}{ NIAC } & \multicolumn{3}{|c|}{ NE II } \\
\hline & $\mathrm{La}^{2}$ & $P y^{2}$ & $\beta-\mathrm{IIBA}^{2}$ & La & Py & $\beta$-IIBA & $\mathrm{La}$ & Py & $\beta$-HBA & $\mathrm{La}$ & Py & $\beta$-HBA \\
\hline & \multicolumn{3}{|c|}{ mmoles/liter } & \multicolumn{3}{|c|}{ mmoles/liter } & \multicolumn{3}{|c|}{ mmoles/liter } & \multicolumn{3}{|c|}{ mmoles/liter } \\
\hline 1 & 2.10 & 0.201 & & 2.72 & 0.235 & & 2.01 & 0.250 & & 2.41 & 0.240 & \\
\hline 2 & 2.17 & 0.133 & & 2.94 & 0.137 & & 2.92 & 0.137 & & 2.81 & 0.153 & \\
\hline 3 & 1.40 & 0.112 & & 2.69 & 0.169 & & 1.93 & 0.141 & & 3.05 & 0.212 & \\
\hline 4 & 1.05 & 0.102 & 0 & 1.79 & 0.175 & 0 & 1.69 & 0.233 & 0 & 2.76 & 0.122 & 0 \\
\hline 5 & 0.50 & 0.153 & 0 & 1.34 & 0.182 & 0 & 1.31 & 0.189 & 0 & 1.63 & 0.154 & 0 \\
\hline 7 & & & 0.084 & & & 0.084 & & & 0.058 & & & 0.052 \\
\hline 9 & 2.16 & & 0.078 & 2.50 & & 0.131 & 2.30 & & 0.055 & 3.42 & & 0.054 \\
\hline 10 & 0.78 & 0.082 & 0.031 & 1.41 & 0.166 & 0.040 & 1.43 & 0.177 & 0 & 3.02 & 0.182 & 0 \\
\hline 13 & 6.09 & 0.496 & 0.050 & 6.82 & 0.449 & 0.054 & 6.26 & 0.577 & 0.040 & 6.82 & 0.502 & 0.043 \\
\hline 14 & 4.48 & 0.353 & 0.060 & 4.62 & 0.369 & 0.055 & 5.03 & 0.461 & 0.028 & 6.67 & 0.591 & 0.032 \\
\hline
\end{tabular}

${ }^{1}$ See text for definition of periods and abbreviations.

${ }^{2}$ La: lactate; py; pyruvate; $\beta$-HBA: D- $\beta$-hydroxybutyrate. 
sampling times can be seen in Fig. 1); those given for NE I and NE II represent the peak values observed.

For each of the variables measured, a comparison has been made between the responses observed in NE I and
NE II (Table III). These comparisons have been made between increment increases of BASAL to NE I with increment increases of NIAC to NE II since administration of nicotinic acid resulted in significant changes in all

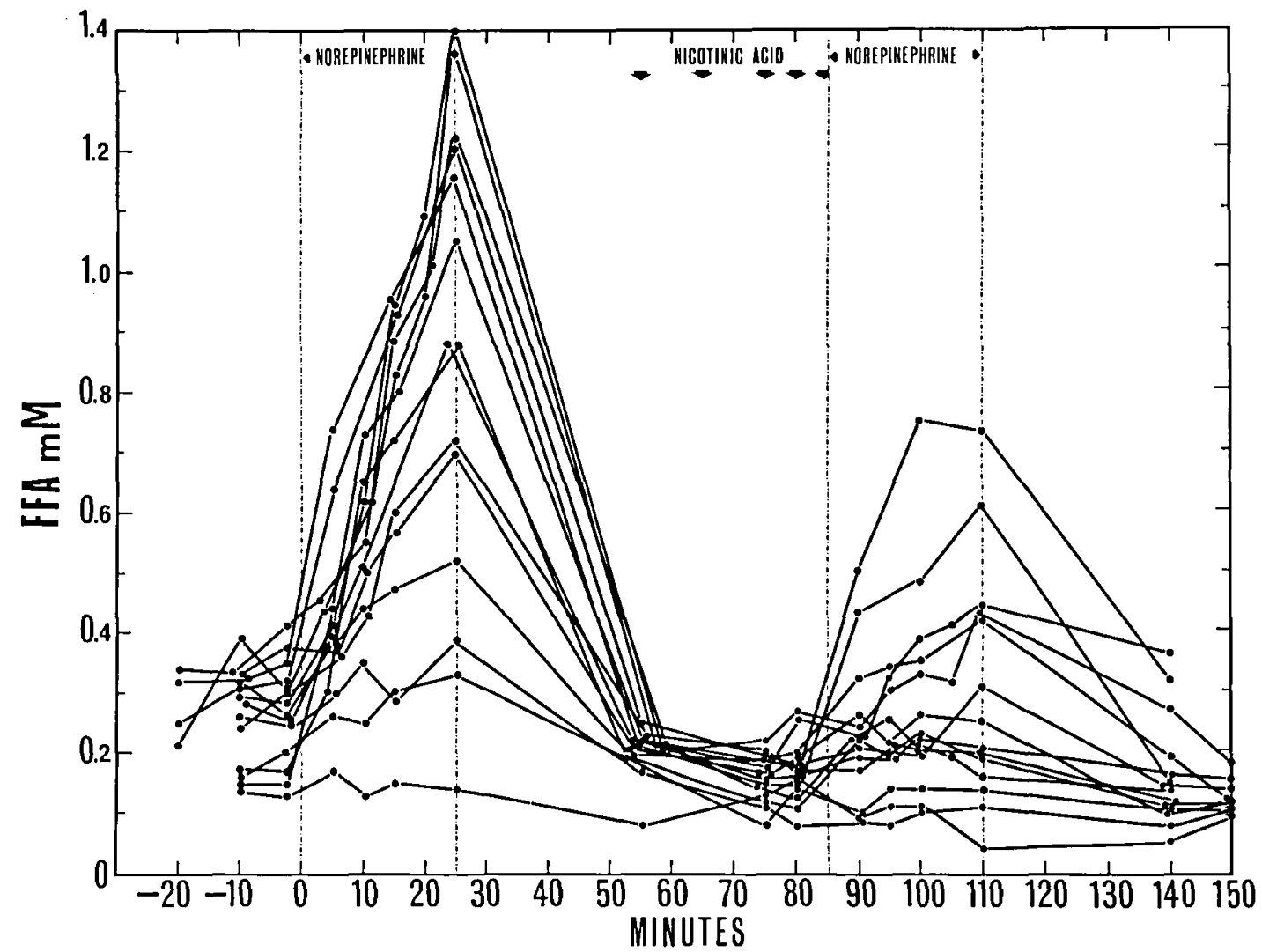

Fig. 1. Changes in free fatty acid (FFA) concentrations in plasma in 14 piglets receiving norepinephrine infusions (2.0 $\mu \mathrm{g} / \mathrm{kg} \cdot \mathrm{min})$ before and after five bolus intravenous injections of nicotinic acid (total of $50 \mathrm{mg} / \mathrm{kg}$ ). Values for individual animals can be obtained by reference to Table II $A$.

Table III. Incremental changes in biochemical variables and oxygen consumption data ${ }^{1}$

\begin{tabular}{|c|c|c|c|c|}
\hline \multirow[b]{2}{*}{ Variables measured } & \multicolumn{4}{|c|}{ Experimental periods } \\
\hline & BASAL $\rightarrow$ NIAC & BASAL $\rightarrow$ NE I & NIAC $\rightarrow$ NE II & $\begin{array}{l}(\text { NIAC } \rightarrow \text { NE II) } \\
(\text { BASAL } \rightarrow \text { NE I) }\end{array}$ \\
\hline FFA, mmoles/ml & $-0.10 \pm 0.02^{2 * * * 3}$ & $0.59 \pm 0.10^{* * *}$ & $0.15 \pm 0.04^{* *}$ & $0.43 \pm 0.08^{* * *}$ \\
\hline Glycerol, mmoles/ml & $-0.025 \pm 0.007^{* *}$ & $0.105 \pm 0.019^{* * *}$ & $0.034 \pm 0.013^{*}$ & $0.080 \pm 0.021^{* *}$ \\
\hline Glucose, $\mathrm{mg} / 100 \mathrm{ml}$ & $20 \pm 6^{* *}$ & $55 \pm 7^{* * *}$ & $51 \pm 11^{* * *}$ & $4 \pm 14$ \\
\hline Lactate, mmoles/liter & $0.46 \pm 0.10^{* *}$ & $0.68 \pm 0.11^{* * *}$ & $0.86 \pm 0.20^{* *}$ & $-0.18 \pm 0.26$ \\
\hline Pyruvate, mmoles/liter & $0.067 \pm 0.015^{* *}$ & $0.031 \pm 0.014$ & $0.010 \pm 0.023$ & $0.021 \pm 0.024$ \\
\hline $\begin{array}{l}\beta \text {-Hydroxybutyrate, } \\
\text { mmoles/liter }\end{array}$ & $-0.024 \pm 0.004^{* * *}$ & $0.008 \pm 0.007$ & $0 \pm 0.002$ & $0.008 \pm 0.007$ \\
\hline Hematocrit, $\%$ & $-2.1 \pm 0.4^{* * *}$ & $1.2 \pm 0.3^{* *}$ & $1.0 \pm 0.4^{*}$ & $0.2 \pm 0.4$ \\
\hline$\dot{\mathrm{V}} \mathrm{O}_{2}, \mathrm{ml} / \mathrm{kg} / \mathrm{min}$ & $-0.11 \pm 0.20$ & $0.85 \pm 0.27^{* *}$ & $0.57 \pm 0.29$ & $0.28 \pm 0.36$ \\
\hline$\dot{\mathrm{V}} \mathrm{O}_{2}, \%$ change & $-0.9 \pm 1.3$ & $6.0 \pm 1.4^{* *}$ & $4.1 \pm 1.8^{*}$ & $1.8 \pm 2.2$ \\
\hline
\end{tabular}

${ }_{1}$ Increment changes, i.e., period $\mathrm{x} \rightarrow$ period $\mathrm{y}$, were calculated as value (period $\mathrm{y}$ ) minus value (period $\mathrm{x}$ ). See text for experimental periods and abbreviations.

2 Mean \pm SEM.

${ }^{* *}: P>0.05,{ }^{* *}: P>0.01,{ }^{* * *}: P>0.001$. 
biochemical variables measured, when compared with BASAL values (Table III). The statistical results were determined by paired comparison $t$ test analyses. The results for $\mathrm{VO}_{2}$ have also been expressed as percentage increasc, i.e., the increment increase expressed as percentage of the preinfusion value.

The mean increases in $\dot{\mathrm{VO}}_{2}$ during both norepinephrine infusion periods were notably small (Table III). There was no significant difference between the $\dot{\mathrm{VO}}_{2}$ responses in NE I and NE II, even though the increases in BASAL $\rightarrow$ NE I (mean of $0.85 \mathrm{ml} / \mathrm{kg} \cdot \mathrm{min}$, or $6.0 \%$ ) were slightly greater than those in NIAC $\rightarrow$ NE II (mean of $0.57 \mathrm{ml} / \mathrm{kg} \cdot \mathrm{min}$, or $4.1 \%$ ). This was true even if the mean increases of BASAL $\rightarrow$ NE I and BASAL $\rightarrow$ NE II were compared. The mean increases of BASAL $\rightarrow$ NE I were significant $(P<0.01)$. During nicotinic acid administration, a mean decrease in $\mathrm{VO}_{2}$ of $0.11 \mathrm{ml} / \mathrm{kg}$. min $(0.9 \%)$ from BASAL values was observed.

The BASAL $\dot{\mathrm{VO}}_{2}$ values, which varied from 6.9 to $20.2 \mathrm{ml} / \mathrm{kg} \cdot \mathrm{min}$ did not show any definite tendency to increase with age after day 2 of life and were lower in the two animals (nos. 7 and 9) starved for $48 \mathrm{hr}$ before testing. During NE I and NE II, one of the starved animals responded with increases and the other with decreases in $\dot{\mathrm{V}} \mathrm{O}_{2}$.

A correlation between age and increment changes in $\dot{\mathrm{VO}}_{2}$ was not found during NE II; during NE I one was found only if the animals over 4 days of age were considered $(r=0.92, P<0.001)$. Since the threc youngest animals had increases comparable to animals over 4 days of agc, however, no significant correlation existed for the wholc group $(r=0.35, P>0.05)$.

Slight rises in both skin and rectal temperatures occurred during NE I and persisted throughout the remaining study periods (mean increases of $0.1^{\circ}$ ). There were no significant differences between the increment changes in temperature occurring in any of the thrce study periods (NE I, NIAC, and NE II), and no correlations between changes in $\mathrm{VO}_{2}$ with changes of either rectal or skin temperatures were found.

During both norepinephrine infusion periods, significant increment increases in FFA and glycerol concentrations in plasma, and glucose and lactate concentrations in blood were observed (Table III). Fyruvate concentrations also rose after norepinephrine administration, but in neither of the two periods were the changes significant. Comparing NE I and NE II, the prior administration of nicotinic acid resulted in significantly lower increases in levels of FFA and glycerol, similar elevations in hematocrit and glucose responses, an insignificant increased cle- vation of lactate concentrations, and an insignificant decreased elevation of pyruvatc concentrations.

$\beta$-Hydroxybutyrate concentrations were very low throughout the period of observation in the seven animals studied. No significant changes occurred during norepinephrine infusions.

The individual patterns of changes in FFA and glycerol concentrations are depicted in Figures 1 and 2, respectively. When an increase in FFA concentration during NE I occurred, it was progressive and reached a peak at $25 \mathrm{~min}$ when norepincphrine infusion was discontinued. A similar response pattern for glyccrol concentrations is shown in Figure 2. Changes in concentrations of FFA and glycerol in individual animals were similar: significant correlations between their peak values in NE I and NE II were found $(r=0.61, P<0.02$ and $r=0.80, P<0.01$, respectively). During NE I, the changes in concentrations of FFA and glycerol and glucose were correlated with the age of the piglet $(r=0.7, P<0.01 ; r=0.86$, $P<0.01 ; r=0.87, P<0.001$, respectively), and changes in FFA concentration were also positively correlated with changes in levels of glucose concentration $(r=0.67, P<0.02)$.

Changes in concentrations of FFA and glycerol and glucose occurring during both NE I and NE II, however, were not correlated with either percentage or incremental changes in $\mathrm{VO}_{2}$. This is well illustrated by the data of four piglets depicted in Figures 3 and 4. The results from two animals, 2.5 and 13 days old, who had similar increases in $\dot{\mathrm{VO}}_{2}$ are shown in Figure 3; and the results from two, $17 \mathrm{hr}$ and 5 days of age, illustrating an absence of or only very small increases in $\dot{\mathrm{VO}}_{2}$ during both $\mathrm{NE}$ I and NE II, are shown in Figure 4. Increases in $\mathrm{VO}_{2}$ occurred in the absence of elevations of FFA and glycerol concentrations during both NE I and NE II (Fig. 3). A similar lack of relation between $\dot{\mathrm{VO}}_{2}$ changes and norepinephrine-induced elevations of lactate, pyruvate, and glucose concentrations is also evident in the figures. During NE II, but not during NE I, there was a correlation between changes in $\dot{\mathrm{VO}}{ }_{2}$ and changes in lactate concentrations $(r=0.75, P<0.02$ and $r=0.76, P<0.02$ for percentage and incremental changes in $\mathrm{VO}_{2}$, respectivcly).

\section{Epinephirine Infusions}

The data for birth weight, age and weight at test, skin and rectal and environmental temperatures, values for $\dot{\mathrm{V}} \mathrm{O}_{2}$, and doses of epinephrine administered to five animals in the two epinephrine infusion periods ( $E$ I and $\mathrm{E} I \mathrm{II})$ are given in Table $\mathrm{I} B$. The increases in $\mathrm{VO}_{2}$ observed during E I (range of $0-14 \%$ or $0-2.6 \mathrm{ml} / \mathrm{kg}$. min) were of the same magnitude as those seen after 


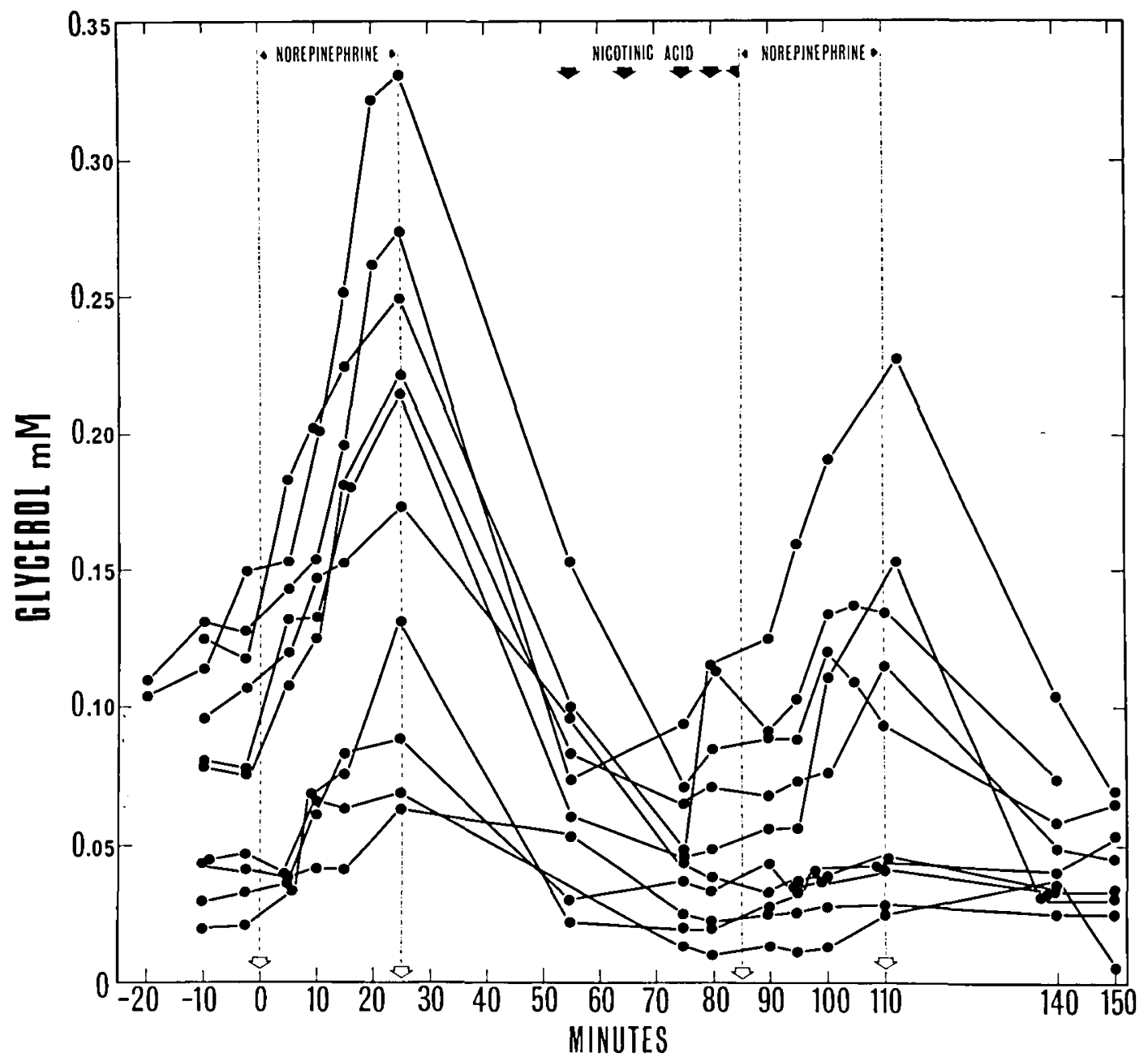

Fig. 2. Changes in glycerol concentrations in plasma in 10 of the 14 animals depicted in Figure 1. Values for individual animals can be obtained by reference to Table II $A$.

norepinephrine infusion. The increases in $\mathrm{VO}_{2}$ during E II were smaller than during E I, even though some of the animals had received a greater dose of epinephrine during $\mathrm{E}$ I. Changes in rectal temperatures were small with a range of $0-+0.5^{\circ}$.

The changes in $\mathrm{VO}_{2}$, rectal temperatures, and concentrations of FFA and glycerol, and glucose and lactate for three animals given epinephrine are shown in Figure 5 . The piglet receiving $2.0 \mu \mathrm{g} / \mathrm{kg} \cdot \mathrm{min}$ had a greater increase in glycerol and lactate concentrations than the animals receiving smaller doses of epinephrine, but the clevation of FFA concentration was similar to that of the animal recciving $0.8 \mu \mathrm{g} / \mathrm{kg} \cdot \mathrm{min}$ of epinephrine. The changes in glucose concentrations were similar at all three doses of epinephrine. There were no consistent relations between increases in $\dot{\mathrm{V}}_{2}$ and increases in concentrations of FFA and glyccrol or glucose.

\section{Discussion}

The results presented are in agreement with previously reported minimal calorigenic responses to norepinephrine in neonatal piglets [18] and miniature piglets [2]. The changes in $\mathrm{VO}_{2}$ observed were not as distinctly age-related as had been reported earlier for piglets of similar ages [18]. No consistent relations were demonstrable between the minimal increases in skin and rectal temperatures and the changes in $\dot{\mathrm{VO}}_{2}$, unlike those seen in other species in which the $\dot{\mathrm{V}}_{2}$ response to norepinephrine was more pronounced $[7,16]$.

Starvation leads to a decrease in basal $\mathrm{VO}_{2}[12]$, and during the first few days of postnatal life basal $\mathrm{VO}_{2}$ rises in fed piglets [11]. Thus the variability in "BASAL" $\dot{\mathrm{V}} \mathrm{O}_{2}$ values in the animals studied can to some extent be accounted for by differences in age and feeding status. 


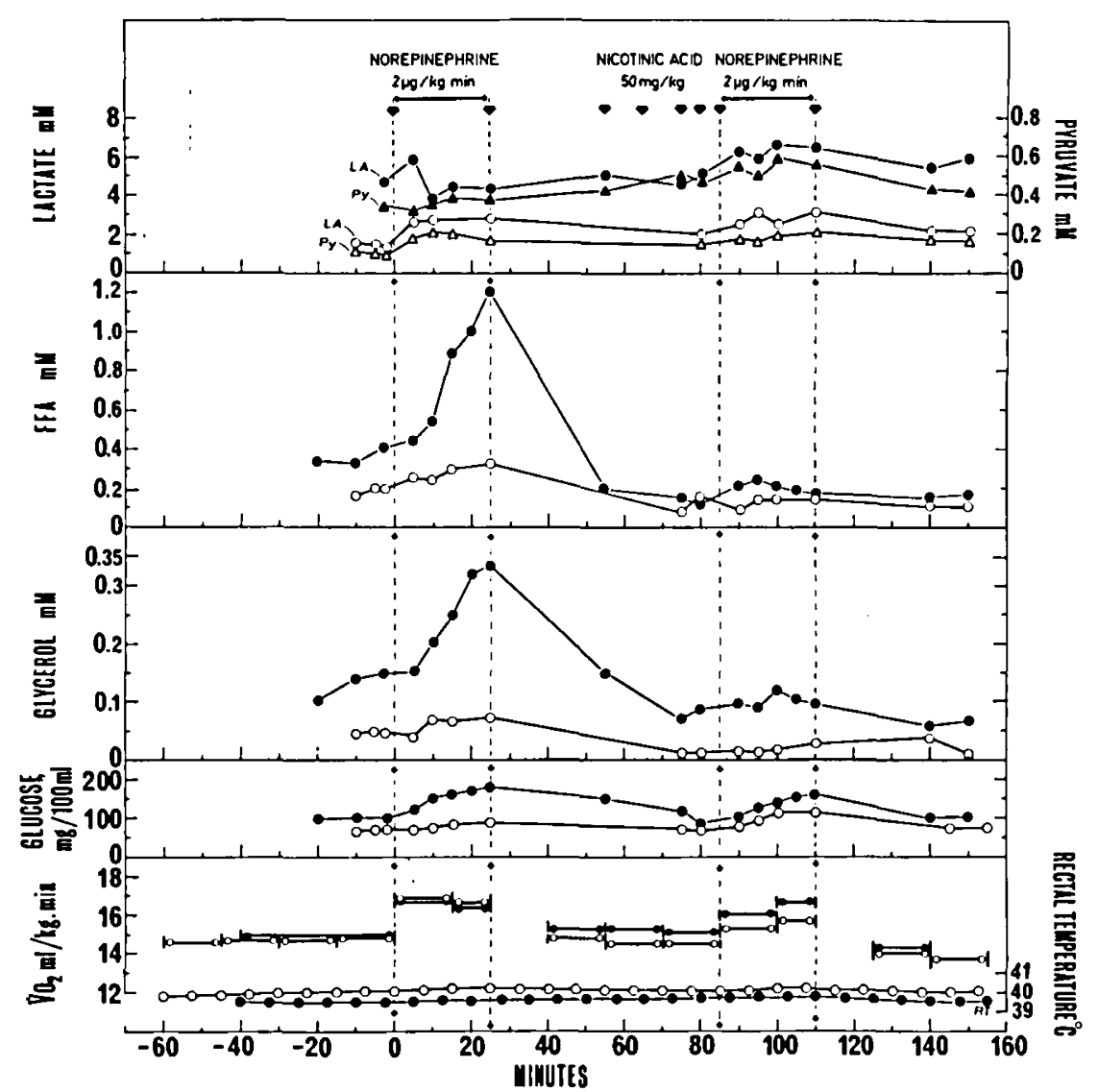

Fig. 3. Changes in biochemical variables in two piglets responding to norepinephrine infusions with similar increases in $\mathrm{VO}_{2}$ rate. For protocol see Figure 1 and text. 0 - $0:$ pig no. 3, 2.5 days of age;

In the five animals infused with epinephrine the magnitude of the calorigenic responses was similar to that seen with comparable doses of norepinephrine. Thus we could not confirm the previous finding in piglets of a relatively greater calorigenic effect of epinephrine as compared with norepinephrine in this age period [18].

The lack of a relation between changes in $\mathrm{V}_{2}$ and hyperglycemia following both norepinephrine and cpinephrine infusions is consistent with the results of studies in newborns of other species $[9,26]$. The clevations of glucose concentrations following norepinephrine infusion increased with increasing postnatal age and were well correlated with the increases in FFA concentrations. This observation, although consistent with the concept of interference of carbohydrate utilization by elevated levels of FFA [21], probably reflects an age-related change in response since similar elevations of glucose concentrations were observed after FFA mobilization had been suppressed by previous administration of nicotinic acid.
Although it has been suggested that part of the calorigenic response to norepinephrine can be directly attributed to the effects of elevations of lactate [9], this relation was not demonstrable when norepinephrine alone was infused. During NE I, elevations of lactate concentrations were not correlated with changes in $\mathrm{VO}_{2}$; during NE II, however, a significant correlation was obtained. Whether this was related to elevated "BASAL" lactate concentrations during NIAC, to the effects of nicotinic acid on glucose metabolism, or to the effects of inhibition of FFA mobilization remains to be defined.

The increases in hematocrit following both norepinephrine stimulation periods can be explained by the increases in interstitial volume and decreases in blood volume that occur after norepinephrine infusion in piglets [5]. The decreases in hematocrit to less than "BASAL" values scen after nicotinic acid administration may reflect the transient changes in redistribution of blood flow that accompany administration of this drug [3].

The elevations of glycerol and FFA concentrations 


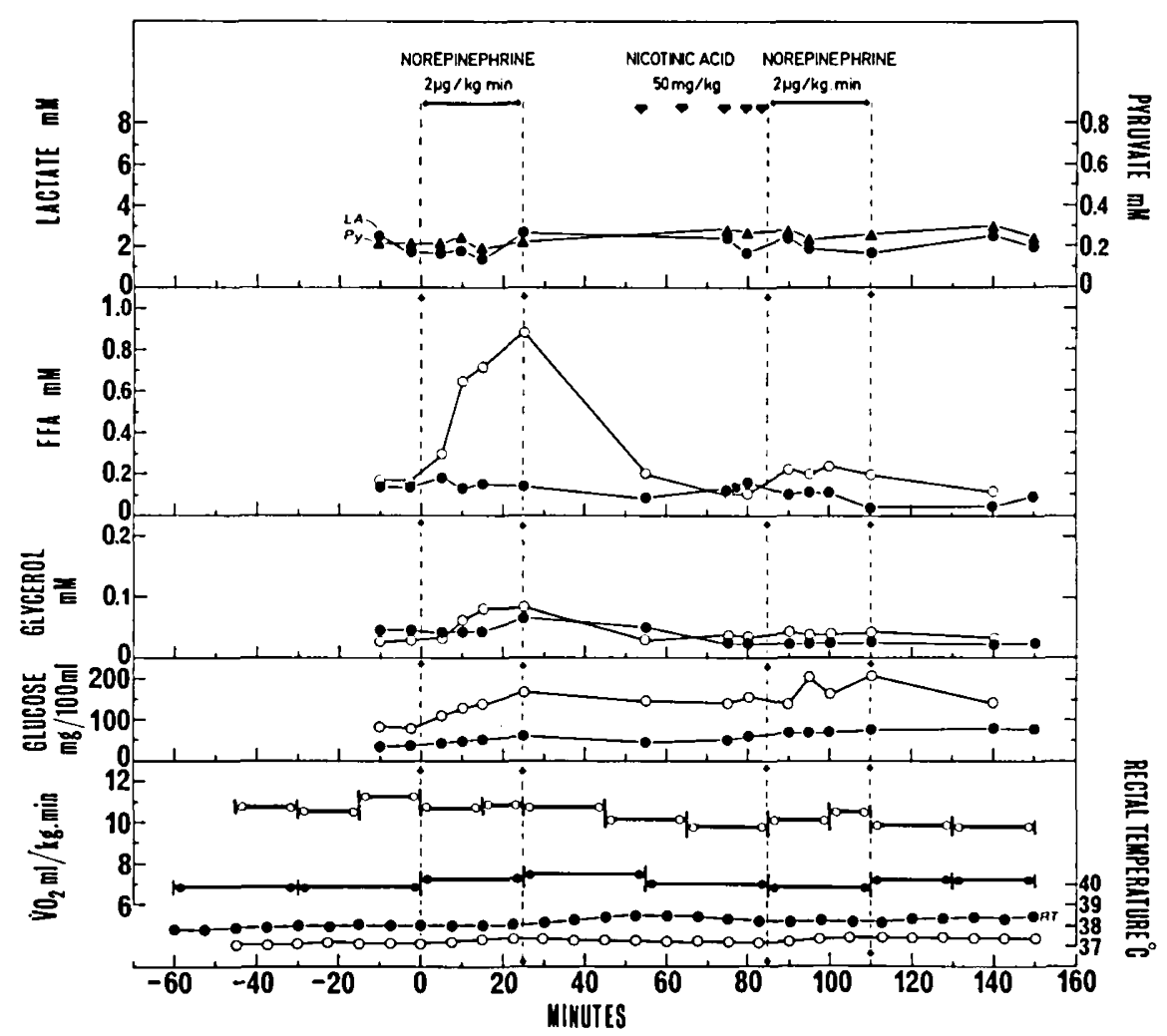

Fig. 4. Changes in biochemical variables in two piglets who show no significant changes in $\dot{\mathrm{V}} \mathrm{O}_{2}$ rate following norepinephrine infusions. For protocol see Figure 1 and text. $\mathrm{O}-\mathrm{O}:$ pig no. 7, 5 days of age; : pig no. $1,17 \mathrm{hr}$ of age.

observed following norepinephrine stimulation have been interpreted to reflect increased lipolysis and lipid mobilization. The validity of this interpretation for piglets has been demonstrated under similar experimental circumstances with ${ }^{14} \mathrm{C}$-palmitic acid infusions: significant increases of plasma FFA turnover occurred following norepinephrine infusion [14].

The observed lipolytic response of newborn piglets to norcpinephrine infusions contradicts the results of previous in vitro studies [22] but is in accordance with in vivo studies in older piglets [6]. Lipid mobilization following norepinephrine infusion increased with postnatal age, was not correlated with changes in $\dot{\mathrm{V}} \mathrm{O}_{2}$, and was significantly suppressed by nicotinic acid. It should be noted, however, that even after a dose of 50 $\mathrm{mg} / \mathrm{kg}$ nicotinic acid, which in other species effects a complete inhibition of lipolysis [15], some of the animals still manifested a mild lipolytic response to norepinephrine.

During the first 2 weeks of life, when the piglet is increasing his body fat content from about $1 \%$ at birth to some $14 \%$ of body weight at 2 weeks of age [17], in- creases in fasting levels of plasma FFA and glycerol concentration have been reported [1]. During this same period the magnitude of the norepinephrine-stimulated lipid mobilization increases, suggesting that age and body stores of adipose tissue may be important determinants of the capacity of the piglet for lipid mobilization.

Even when norepinephrine did effect lipid mobilization, however, increases in $\mathrm{VO}_{2}$ were notably small and were not related to the lipolytic responses. Suppression of FFA mobilization during norepinephrine infusion did not significantly alter $\dot{\mathrm{O}}_{2}$ responses. These findings could reflect the influence of factors such as nutritional status or the magnitude of the lipid-mobilizing response. In adult humans the $\mathrm{VO}_{2}$ response to norepinephrine infusion appears to be related to the nutritional status of the individual, and the lack of a response in the postprandial state has been attributed to a lack of FFA mobilization [15]. Starvation prior to norepinephrine infusion in the two piglets studied, however, did not appear to accentuate the $\dot{\mathrm{VO}}_{2}$ response. The maximal increases in FFA concentrations following norepinephrine infusions, in most of the piglets studied, were com- 


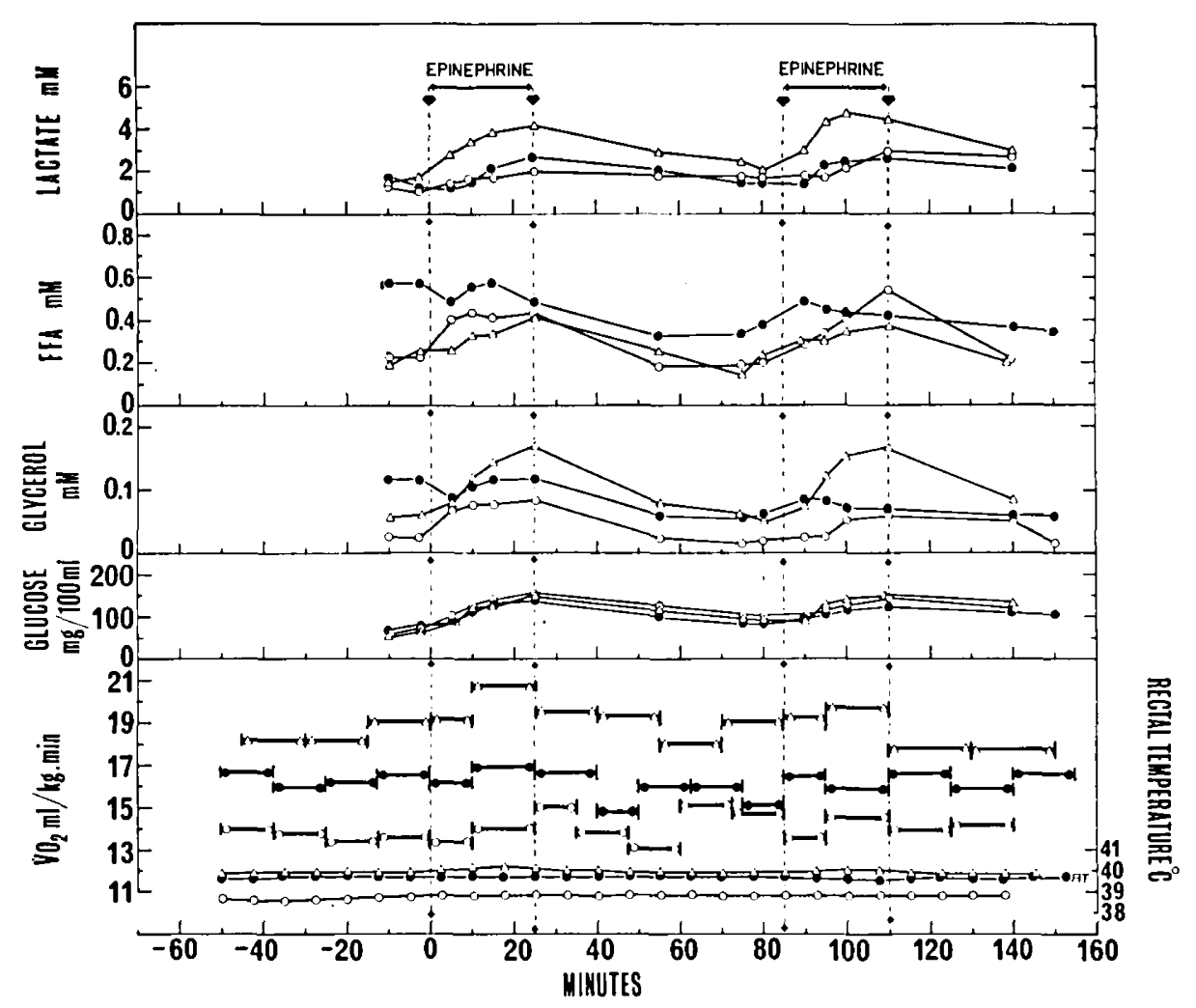

Fig. 5. Changes in biochenical variables and $\mathrm{V}_{2}$ rate in three piglets receiving intravenous epinephrine in two infusion periods. For dosage see Table IB. - : pig no. 17, 8 days of age; $\triangle-\triangle$ : pig no. 18, 8 days of age; $\bigcirc-O:$ pig no. 19, 11 days of age.

parable to those seen in other species $[8,15,28]$, including the human newborn [24]. In all these species, however, a substantial increasc in $\dot{\mathrm{VO}}_{2}$ accompanied the lipolytic response to infused norcpinephrine.

It therefore seems likcly that in the newborn piglet the lack of an appreciable increase in $\mathrm{VO}_{2}$ after norepinephrine infusion reflects an altered utilization of mobilized FFA, probably a relative lack of oxidation. This suggestion is supported by the finding of a lack of an increase in ketonc bodies following norepinephrine infusion. Whether or not this explanation can be interpreted simply to reflect a lack of brown adipose tissuc remains to be defined. Preliminary results in older piglets indicate, however, that oxidative utilization of FFA mobilized during norepinephrine infusion improves with increasing postnatal age [14]. It is therefore unlikely that the absence of brown adipose tissue alone could account for the suggested relative lack of oxidative utilization of mobilized FFA in newborn piglets.

\section{Summary}

Our findings in the piglet and the recent report suggesting that white adipose tissue of newborn human infants differs metabolically in its response to norepinephrine [19] suggest that investigations into the rolc of white adipose tissue in the norepincphrinc-induced calorigenic response of newborns of various species are of importance.

\section{References and Noles}

I. Bingitsion, G., Gentz, J., Hakkarainen, J., Hellström, R., And Persson, B.: Plasma levels of FFA, glycerol, $\beta$-hydroxybutyrate and blood glucose during the postnatal develop. ment of the pig. J. Nutr., 97: 311 (1969).

2. BRüCK, K., WÜNNenderG, W., AND ZeISbERGer, E.: Comparison of cold-adaptive metabolic modifications in different species, with special reference to the miniature pig. Fed. Proc., 28: 1035 (1969).

3. Carlson, L. A., Freyschuuss, U., Kjellberg, J., and Östman, J.: Suppression of splanchnic ketone body production on man by nicotinic acid. Diabetologia, $3: 494$ (1967).

4. Carlson, L. A., AND Orö, L.: The effect of nicotinic acid on the plasma frce fatty acid: Demonstration of a metabolic type of sympathicolysis. Acta Med. Scand., 172: 641 (1962).

5. CheEK, D. B., AND Rowe, R. D.: Aspects of sympathetic activity in the newborn, including the respiratory distress syndrome. Pediat. Clin. N. Amer., 13: 863 (1966).

6. Cunningham, H. M., and Friend, D. W.: Influence of epinephrine, norepinephrine and nicotine on blood levels of glucose, free fatty acids and amino nitrogen in pigs. Can. J. Anim. Sci., $2 f$ : 41 (1965). 
7. Dawes, G. S.: Foetal and Neonatal Physiology: A Comparative Study of the Changes at Birth (Year Book Medical Publishers, Chicago, 1968).

8. Dawkins, M. J. R., AND Hull, D.: Brown adipose tisste and non-shivering thermogenesis in newborn animals. In: J. II. P. Jonxis, H. K. A. Visser, J. A. Troelstra, H. E. Stenfert, and N. V. Kroese: The Adaptation of the Newborn Infant to Extra-uterine Life, p. 269 (Leiden, 1964).

9. Dzedin, T., Lundiolm, L., ANd Svedmr, N.: Relationship between some metabolic effects of nicotinic acid and cate. cholamines in the rabbit. Acta Pharmacol. Toxicol., 26: 446 (1968).

10. Eaton, P., and Steinberg, D.: Effects of medium fatty acid concentration, epinephrine, and glucose on palmitate-1-C $\mathrm{C}^{14}$ oxidation and incorporation into neutral lipids by skeletal muscle in vitro. J. Lipid Res., 2: 370 (1961).

11. Gentz, J., Bengtsson, G., Hakarainen, J., Hellström, R., AND Persson, B.: Factors influencing oxygen consumption in in the newborn pig with special reference to feeding. Biol. Neonatorum, 16: 328 (1970).

12. Gentz, J., Bengtsson, G., Hakkarainen, J., Hellström, R., and Persson, B.: Metabolic effects of starvation during neonatal period in the piglet. Amer. J. Physiol., 218: 662 (1970).

13. Gentz, J., Persson, B., Hakarainen, J., and Lindstedt, S.: Apparatus for measurement of oxygen consumption and the production of $\mathrm{CO}_{2}$ and ${ }^{14} \mathrm{CO}_{2}$ in small subjects under controlled cnvironmental conditions. J. Appl. Physiol., 29: 731 (1970).

14. Gentz, J., Persson, B., And Kel.lum, M. J.: Unpublished obscrvations.

15. Havel, R. J., Carlson, L. A., Ekelund, L., and Holmgren, A.: Studies on the relation between mobilization of free fatty acids and energy metabolism in man; Effects of norepinephrine and nicotinic acid. Metabolism, 13: 1402 (1964).

16. Karlberg, P., Moore, R. E., ANd Oliver, T. K.: Thermogenic and cardio-vascular responses of the newborn baby to noradrenaline. Acta Pacdiat. Scand., 5t: 225 (1965).

17. Manners, M. J., ANd McCrea, M. R.: Changes in the chemical composition of sow-reared piglets during the first month of life. Brit. J. Nutr., 17: 495 (1963).

18. Mount, L. E.: Effects of noradrenaline and adrenaline on oxygen consumption rate and arterial blood pressure in the newborn pig. Nature, 217: 77 (1968).

19. NovÂk, M., Meclichar, V., AND Haiın, P.: Postnatal development of human adipose tissue, oxygen consumption, and oxidation of fatty acids. Biol. Neonatorum, 14: 203 (1969).

20. Persson, B.: Determination of plasma acetoacetate and $D-\beta$ hydroxybutyrate in new-born infants by an enzymatic fluoro- metric micromethod. Scand. J. Clin. Lab. Invest., 25: 9 (1970).

21. Rande, P. J.: The interrelations of hormones, fatty acid and glucose in the provision of energy. Postgrad. Med. J., 40: 457 (1964).

22. Rudman, D., Brown, S. J., and Malkin, M. F.: Adipokinetic actions of adrenocorticotropin, thyroid-stimulating hormone, vasopressin $\alpha$ - and $\beta$-melanocyte-stimulating hormones, fraction $\mathrm{H}$, cpincphrine and norepinephrine in the rabbit, guinea pig, hamster, rat, pig and dog. Endocrinology, 72: 527 (1962).

23. Sandeer, M., Rutinen, C. R. J., Normand, K. S., and Moore, R. E.: Environmental temperature and urinary excretion of 3-methoxy-4-hydroxy-mandelic acid in the newborn. Lancet, 2SO: 485 (1961).

24. ScinfF, D., Stern, L., And Leduc, J.: Chemical thermogenesis in newborn infants: Catecholamine excretion and the plasma nonesterified fatty acid response to cold exposure. Pediatrics, 37: 577 (1966).

25. Scholz, R., Schimitz, H., Bücher, T., and Lampen, J. O.: Uber die Wirkung von Nystatin auf Bäckerhefe. Biochem. Z., 331: 71 (1959).

26. Scopes, J. W., ANd Tizard, J. P. M.: The effect of intravenous noradrenaline on the oxygen consumption of new-born mammals. J. Physiol., 165: 305 (1963).

27. SMITI, R. E., AND HoRwitz, B. A.: Brown fat and thermogenesis. Physiol. Rev., 49: 330 (1969).

28. Steinnerg, D., Nestel, P. T., Buskirk, E. R., and Thompson, R. N.: Calorogenic effect of norepinephrine correlated with plasma free fatty acid turnover and oxidation. J. Clin. Invest., 43: 167 (1964).

29. Type Z8, Elab A/S, Copenhagen, Denmark.

30. Xylocaine,

31. Unita 1, B, Braun Apparate Bau, Melzangen, Germany.

32. Nor-Exadrin conc., Astra, Sweden.

33. Nikotinsyra, $A C O$, Sweden.

34. Adrenaline, ACO, Sweden.

35. W' are grateful to Professors S. Lindstedt, L. A. Carlson, and R. Zetterström for critically reading the manuscript; and A. Axelsson, K. Forsberg, L. Gustafson, and E. Söderberg for technical assistance.

36. Supported by grants from Karolinska Institutet, Reservationsanslaget, and Semper Fond för Näringsforskning.

37. Dr. Michacl Kellum is a traince in Nconatology supported by funds from the Littman Foundation, Minneapolis, Minn.

38. Requests for reprints should be addressed to: Bengt Persson, S:t Göran's Children's Hospital, Box 12500, S-112 81 Stockholm, Sweden.

39. Accepted for publication November 2, 1970. 